\title{
Dens invagination and root dilaceration in double multilobed mesiodentes in 14-year-old patient with anorexia nervosa
}

\author{
J. Bagińska1', E. Rodakowska², Sz. Piszczatowski³ , A. Kierklo¹, E. Duraj ${ }^{4}$ J. Konstantynowicz ${ }^{5}$ \\ ${ }^{1}$ Department of Dentistry Propaedeutics, Medical University of Bialystok, Poland \\ ${ }^{2}$ Department of Restorative Dentistry, Medical University of Bialystok, Poland \\ ${ }^{3}$ Faculty of Mechanical Engineering, Bialystok University of Technology, Bialystok, Poland \\ ${ }^{4}$ Department of Periodontal and Oral Mucosa Diseases, Medical University of Bialystok, Poland \\ ${ }^{5}$ Department of Paediatrics and Developmental Disorders, Medical University of Bialystok, Poland
}

[Received: 16 June 2016; Accepted: 1 August 2016]

This paper describes a rare case of erupted double supernumerary teeth with unusual morphology in a 14-year-old patient with an eating disorder. The coexistence of dental morphological anomalies: multilobed mesiodens, multiple dens in dente of different types and root dilaceration have not been previously reported. The paper highlights anatomical and radiological aspects of dental abnormalities and clinical implications of delayed treatment. (Folia Morphol 2017; 76, 1: 128-133)

Key words: supernumerary teeth, mesiodens, dens in dente, root dilacerations, computed tomography

\section{INTRODUCTION}

There are several dental abnormalities, including changes in the number of teeth and deformities in crown morphology, root formation or pulp cavity composition. Dental anomalies may be caused by genetic factors or by developmental or metabolic disturbances.

Hyperdontia is a condition involving the presence of a tooth or teeth additionally to the normal series. Hyperdontia occurs singly or multiply up to $90 \%$ in the central incisor region, more often in the permanent dentition and in males [20]. A supernumerary tooth located in the maxillary midline region is called a mesiodens [20]. The prevalence of mesiodentes ranges between $0.09 \%$ and $2.05 \%$, with a higher frequency in people of Asian ethnicity $[4,6]$.

Supernumerary teeth are classified according to their morphology into two types: supplemental (eumorphic), with normal size and shape, and rudimentary (dysmorphic), smaller and of abnormal shape [17].
The shape of rudimentary mesiodens is mostly conical (peg-shaped, canine-like). Less often the crown is complicated with many tubercules (tuberculated, lobular-like) or is molariform. A multilobed mesiodens with 4 or 5 lobes is a rare finding $[6,19]$. As a rule, the root of a conical mesiodens is normally formed, while other-shaped mesiodentes may have incompletely developed roots [17].

Due to the lack of embryological evidence, the aetiology of supernumerary teeth is still hypothetical $[4,17,20]$. There are three widely discussed theories: phylogenetic reversion (atavism), dichotomy and hyperactivity of dental lamina. The most supported theory suggests that a mesiodens develops as a result of a local hyperactivity of dental lamina, which induces the development of an extra tooth bud $[4,20]$. An accessory tooth bud results in the formation a supplemental tooth, while the epithelial remnants of dental lamina are the source of rudimentary teeth [4]. A mesiodens may be detected isolated or with crani- 
ofacial anomalies like lip or palate cleft, Gardner's syndrome, cleidocranial dysostosis [20]. The occurrence of mesiodentes among first-degree relatives is explained by the genetic basis of their development, with the autosomal dominant inheritance with incomplete penetration $[3,20]$. An acute intrusive trauma to primary incisors is also considered a risk factor [9].

A supernumerary tooth may be fully or partially erupted, or may remain impacted, and be found accidentally during a radiological investigation [7]. In a half of cases, the presence of mesiodens prevents or delays the eruption of front teeth; the adjacent incisors are usually labially displaced. Other complications in central incisors involve the rotation, root resorption, root dilaceration and pulp necrosis [20].

Another abnormality typical for the upper front region is dens invaginatus, also called dens in dente. The anomaly is diagnosed radiologically as an infolding of enamel and dentine extending into pulp cavity and in some cases reaching the root apex $[10,21]$. The most affected teeth are maxillary lateral incisors, but cases of dental invagination in other, including supernumerary, teeth were also presented $[1,11,21]$.

The aetiology of dens in dente is unclear and many theories have been presented so far: among others, genetic factors, infection, dental trauma, fusion of two germs and disturbance of the internal enamel epithelium were discussed [11]. Some authors claim that the anomaly is a result of a deep folding of the foramen caecum during the tooth development causing, in some cases, a second apical foramen [11]. Moreover, dens invaginatus is often found in patients with associated dental abnormalities.

The most widely used classification of dens invaginatus was proposed by Oehler et al. [15] who divided such teeth into three groups. In type I, the invagination is limited to the coronary portion of the tooth and it does not extend beyond the cementoenamel junction. In type II, it extends beyond the cementoenamel junction and is retained inside the main canal. In types I and II, the invaginations is incomplete and it ends as a blind sac without communication with the periodontal ligament. Type III, a complete invagination, occurs when it penetrates the root up to its apex and forms a second foramen in the lateral (IIIA) or apical (IIIB) area [15].

The diagnosis of dens invaginatus is based on radiography and in many cases the anomaly is found by accident [5]. Crowns and roots of dens invaginatus show different shapes and sizes; they can be normal or conical, peg-shaped, barrel-shaped [11]. A tooth morphology showing deep grooves may suggest the presence of an invagination. The pulp of such teeth shows a tendency to necrosis due to the presence of a junction between oral cavity and pulp; however, the pulp may remain vital if the invagination has no communication with the root canal $[18,21]$.

Root dilaceration is a morphological disturbance defined as an altered position of the tooth root relative to the crown. It is diagnosed if a root or sometimes a crown shows a severe distortion or bend. The most typical locations are maxillary incisors and mandibular molars; there is also a report on dilaceration in a mesiodens [6]. The aetiology is not clearly understood and, with respect to the anterior teeth, cases of dilacerations are most often explained by a traumatic injury to primary predecessors. Possible reasons of dilaceration are also scar formation, advanced root canal infection, ectopic tooth position, lack of space, effect of other anatomical or pathological structures (for example nasal fossa or supernumerary teeth). The malformation is also associated with some congenital syndromes [12].

Mesial and distal root angulations are easily detectable during radiographic examination, but a dilaceration in the bucco-labial direction may cause a diagnostic problem - in such teeth 'the bull's-eye' phenomena occurs [12]. Nowadays, a cone beam computed tomography (CBCT) scan should be performed to determine the exact position of an angulation. Root dilaceration may result in tooth impaction, which makes it necessary, in case of anterior teeth, to use complicated orthodontic-surgical treatment.

We present the anatomical and radiological aspects of a rare case of bilateral multilobed mesiodentes with a complex external and internal morphology in an adolescent patient suffering from anorexia nervosa.

\section{CASE REPORT}

A female patient aged 14 years and 6 months was admitted to the Department of Paediatrics due to a loss of appetite, a secondary amenorrhea, a significant excessive weight loss of about $17 \mathrm{~kg}$ within preceding 6 months, and a deterioration of general somatic status. Her body mass index was below the $3^{\text {rd }}$ percentile and her pubertal stage ascertained by a physician was Tanner 4. Approximately 1 year before the admission, the girl was diagnosed with anorexia nervosa according to the standard DSM-V criteria [10]. 
Laboratory results revealed an extremely low concentration of vitamin $\mathrm{D}$ (total 25-hydroxyvitamin D was $3 \mathrm{ng} / \mathrm{mL}$ ), though the calcium-phosphate metabolism was normal, and no endocrine disorders were found. The bone mineral density (BMD) of the whole skeleton (total body less head), and the BMD in the lumbar spine region (vertebrae L1-L4) were normal (Age-matched Z-scores were 0.1 and 0.5, respectively). The total body fat was $20.3 \%$ and the fat/lean ratio indicated normal proportions of the body composition reflecting typical features for age, sex and pubertal stage.

Dental examination revealed bilateral multilobed mesiodentes in the position of central incisors in maxilla (Fig. 1). The right central incisor was halferupted labially to the mesiodens and the left one was still unerupted. There were bilateral crowdings of front teeth with a persistent left primary canine. According to parental report, the eruption and shape of the primary teeth were normal and girl had not suffered from any injury to primary teeth. She lost primary central incisors at the age of seven. Four years later, mesiodentes erupted followed by the eruption of the right incisor. During the period between the exfoliation of primary incisors and the eruption of mesiodentes, no X-ray examination was performed. The girl learned to conceal front teeth with her upper lip while speaking or smiling, so it would be hardly visible for a non-professional.

At the age of 13 she was referred to the private dental clinic were CBCT was performed (Fig. 2). The scans confirmed the diagnosis of bilateral multilobed one-rooted mesiodentes. The examination also revealed the exact location of partially impacted central incisors and fully impacted left central incisor and canine. The position of right incisor was labial and parallel to right mesiodens, while left incisor was located horizontally and superior to left mesiodens. Moreover, an unusual internal morphology showing dens invaginatus in mesiodentes was found (Fig. 3). The treatment was delayed because of the patient's poor compliance associated with the underlying general disease; however, in September 2015, the improvement of her psychological and physical state allowed to remove supernumerary teeth and to start orthodontic treatment.

Extracted teeth were carefully examined with $\times 2.5$ magnifying dental loupes (Fig. 4). Both mesiodentes had barrel-like crowns and fully developed roots with close apices. Two lobes were located la-

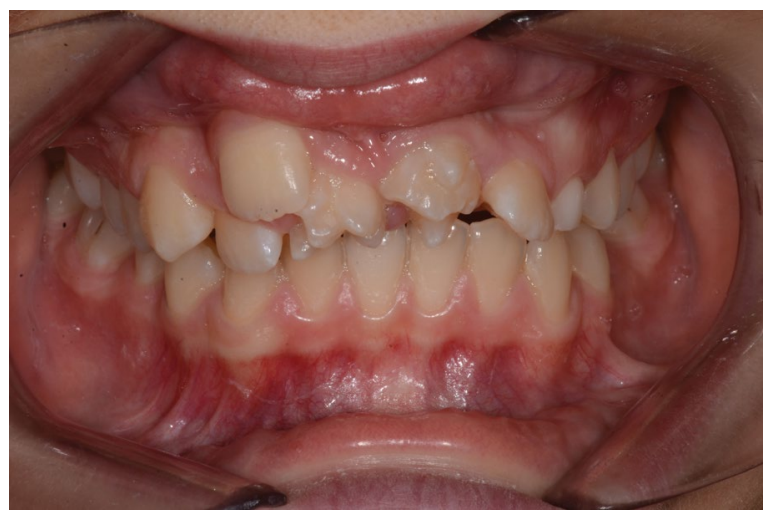

Figure 1. Clinical view of bilateral multilobed mesiodentes in a 14-year-old girl.

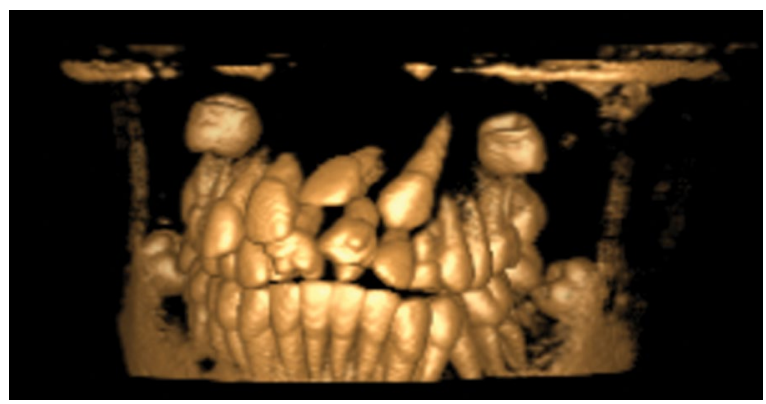

Figure 2. Three-dimensional reconstruction of patient's dentition based on a cone beam computed tomography scan.

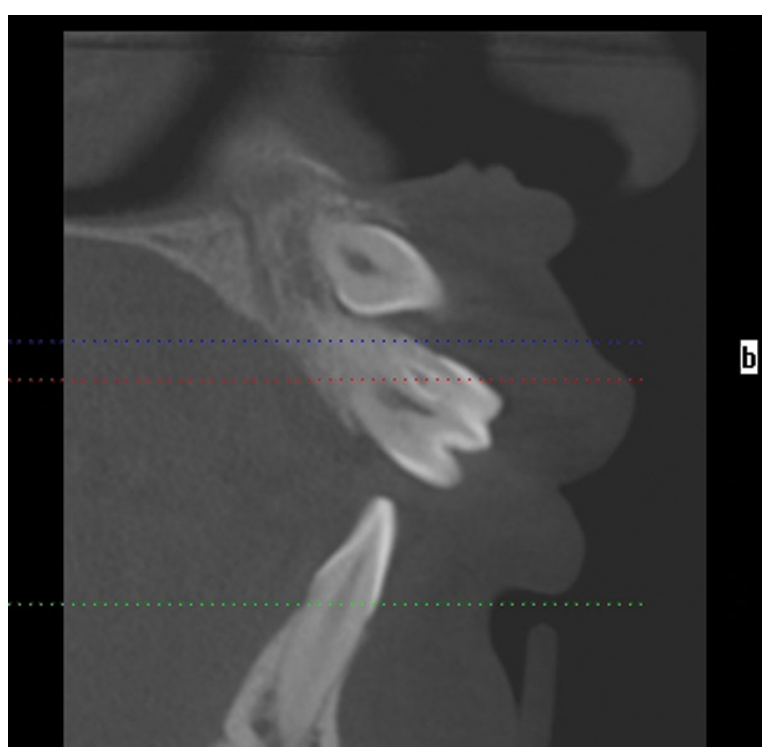

Figure 3. Cone beam computed tomography sagittal section of the left mesiodens.

bially, two palatally with the most massive central lobe. Deep developmental grooves could be observed between lobes. The root of the left mesiodens was 


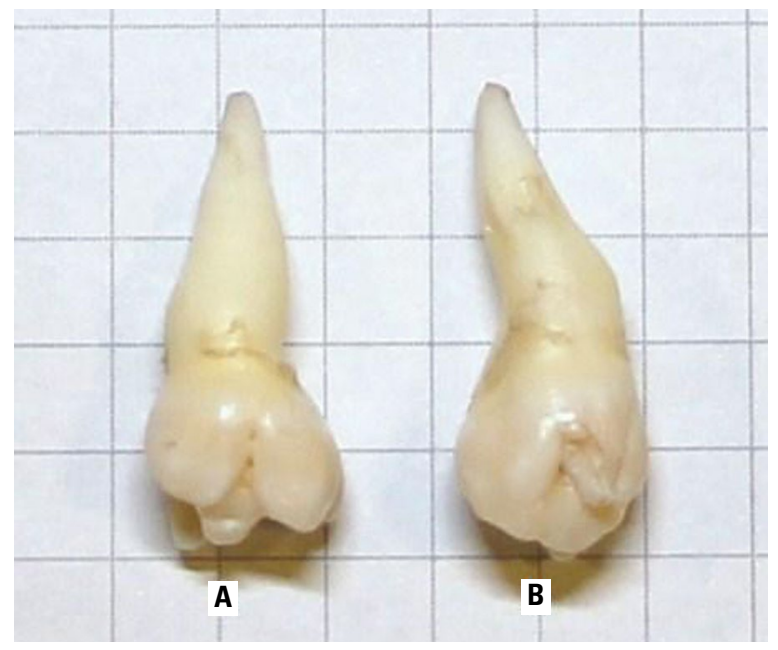

Figure 4. Extracted mesiodentes, A. Right mesiodens; B. Left mesiodens.

dilacerated and two additional apical foramina were revealed on the labial surface. Subsequently, the teeth were scanned using the Skyscan 1172 apparatus (Skyscan, Kontich, Belgium). Axial slices were obtained as bitmaps with the dimensions of $2000 \times$ $\times 2000$, with the pixel size equal to $6 \mu \mathrm{m}$. The distance between neighbouring slices was equal to the pixel size. Obtained data were processed using the Mimics (Materialise, Belgium) software. The microcomputed tomography (microCT) showed details of inner morphology: two dentes in dente of type I in the right mesiodens and two dentes in dente types I and III, and a lateral root canal running from the main canal near to the dens invaginatus and having a junction with its pulp cavity in left mesiodens (Fig. 5). Inside the dens invaginatus type III, a radiopaque tissue of unknown origin was found.

\section{DISCUSSION}

The coexistence of dens invaginatus and root dilaceration in a mesiodens has not been presented so far. The aetiology of dental abnormalities in our patient remains unclear. No supernumerary teeth in firstdegree relatives have been found. The patient did not show any other anomalies in the number or shape of teeth and no associated congenital syndromes were diagnosed. A traumatic injury to primary front teeth is a shared risk factor of all identified abnormalities, but the patient's mother denied that the girl had suffered an injury to primary upper teeth. The hyperactivity of dental lamina may explain the development of multilobed mesiodentes [6], but it does not explain other malformations found in this case.

The use of CBCT in dental diagnostics made it possible to perform a 3-dimensional assessment of craniofacial structures with a relatively low radiation dose; however, the resolution of such devices remains at a lower level compared to microCT scanners. Rajasekharan et al. [18] proved that CBCT was not sufficient to detect the point of entry of irritants from oral cavity into the invagination or to indicate the proximity of invagination to the pulp chamber, but it was possible on microCT scans. Our study supports other reports on higher accuracy of microCT in comparison to digital radiographs, $\mathrm{CT}, \mathrm{CBCT}$ and magnetic resonance imaging scans for the evaluation of dental abnormalities $[13,16,18]$. In our case, the radiopaque tissue of unknown origin was found inside the type III invagination. The presence of hard tissue inside dens in dente was confirmed by Uysal et al. [21] in the light microscopy. They also found several pathologies in the histological structure: irregular dentin tubules and enamel, immature pulp

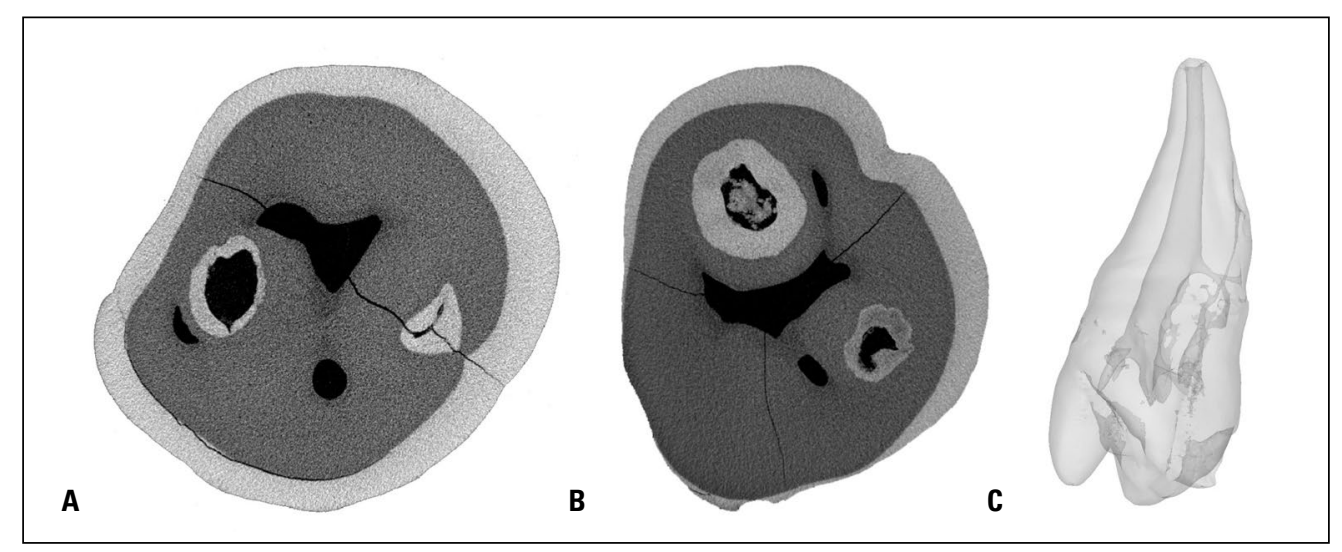

Figure 5. Micro-computed tomography scans of both mesiodentes, A. Axial section of right mesiodens; B. Axial section of left mesiodens; C. Three-dimensional reconstruction of left mesiodens. 
organisation and calcified (bone-like) connective tissue in the pulp.

In our patient, the supernumerary teeth caused several complications in the pattern and place of eruption of upper teeth, with the horizontal position and full impaction of left central incisor being most severe. It is ambiguous why similarly positioned mesiodentes caused different locations of contralateral incisors and why the dilaceration was found only in left mesiodens. Other complications in permanent incisors often caused by supernumerary teeth, e.g. root dilaceration or resorption, were not observed; however, at the time when this paper was written, the dental pulp condition could not be assessed.

The associations between supernumerary teeth and anorexia nervosa found in our patient may be regarded, in a sense, as unusual. There is scarce literature available on possible associations between dental anomalies and eating disorders [14]. In the era of pressure exerted on young people to achieve the perfect look, dental abnormalities may lead to an aesthetic impairment, a decreased self-esteem and psychological disturbances. Rodd et al. [19] proved that abnormal incisor aesthetic was associated with a higher level of dissatisfaction with the appearance and had a negative impact on OHRQoL in 10-11-year-old children. It seems perplexing to us why a delay in eruption of permanent incisors did not cause concerns in parents, a school nurse or a dentist. Every child with a delay in eruption of permanent incisor exceeding 6 months should be carefully diagnosed with regard to possible occurrence of supernumerary teeth [4]. If it remains undetected by radiographs, the $\mathrm{CBCT}$ is recommended [2]. Once diagnosed, a mesiodens in permanent dentition should be surgically removed to prevent complications in the eruption path and the position of teeth associated with it. Such approach significantly minimises the need for subsequent orthodontic treatment. If the extraction is postponed, the multidisciplinary management is often required: a surgical exposure of impacted incisor and a subsequent orthodontic treatment due to diminishing of normal eruption forces in teeth with close apex and limited space $[2,8,20]$. Undoubtedly, in the presented case, the diagnosis and treatment should have been done much earlier. Therefore, the question arises whether the dental abnormality may be responsible for triggering her body image disturbance, anorexic behaviours and psychological problems. Probably the improvement of oral health may be conceivably as critical as psychological support and cognitive-behavioural therapy in the restoration of body weight.

\section{REFERENCES}

1. Archer WH, Silverman LM. Double dens in dente in bilateral rudimentary supernumerary central incisors (mesiodens). Oral Surg. Oral Med. Oral Pathol. 1950; 3(6): 722-726, doi: 10.1016/0030-4220(50)90268-4, indexed in Pubmed: 15423867.

2. Ayers E, Kennedy D, Wiebe C. Clinical recommendations for management of mesiodens and unerupted permanent maxillary central incisors. Eur Arch Paediatr Dent. 2014; 15(6): 421-428, doi: 10.1007/s40368-014-0132-1, indexed in Pubmed: 24994110.

3. Brook $\mathrm{AH}$. A unifying aetiological explanation for anomalies of human tooth number and size. Arch. Oral Biol. 1984; 29(5): 373-378, doi:10.1016/0003-9969(84)901638, indexed in Pubmed: 6611147.

4. Cho SY, So FH, Lee CK, et al. Late forming supernumerary tooth in the premaxilla: a case report. Int J Paediatr Dent. 2000; 10(4): 335-340, doi:10.1046/j.1365263x.2000.00228.x, indexed in Pubmed: 11310248.

5. Colak H, Tan E, Aylıkçı BU, et al. Radiographic study of the prevalence of dens invaginatus in a sample set of Turkish dental patients. J Clin Imaging Sci. 2012; 2: 34, doi: 10.4103/2156-7514.97755, indexed in Pubmed: 22919548.

6. Dave B, Patel J, Swadas M, et al. Multilobed mesiodens: a supernumerary tooth with unusual morphology. BMJ Case Rep. 2013; 2013, doi:10.1136/bcr-2012-008088, indexed in Pubmed: 23391956.

7. Das S, Suri RK, Kapur V. A supernumerary maxillary tooth: its topographical anatomy and its clinical implications. Folia Morphol. (Warsz). 2004; 63(4): 507-509, indexed in Pubmed: 15712152.

8. De Oliveira Gomes C, Drummond SN, Jham BC, et al. A survey of 460 supernumerary teeth in Brazilian children and adolescents. Int J Paediatr Dent. 2008; 18(2): 98-106, doi: 10.1111/j.1365-263X.2007.00862.x, indexed in Pubmed: 18237292.

9. Diab M, elBadrawy HE. Intrusion injuries of primary incisors. Part III: Effects on the permanent successors. Quintessence Int. 2000; 31(6): 377-384, indexed in Pubmed: 11203953.

10. Herpertz-Dahlmann B. Adolescent eating disorders: update on definitions, symptomatology, epidemiology, and comorbidity. Child Adolesc Psychiatr Clin N Am. 2015; 24(1): 177-196, doi: 10.1016/j.chc.2014.08.003, indexed in Pubmed: 25455581.

11. Hülsmann M. Dens invaginatus: aetiology, classification, prevalence, diagnosis, and treatment considerations. Int Endod J. 1997; 30(2): 79-90, doi:10.1111/j.1365-2591.1997. tb00679.x, indexed in Pubmed: 10332241.

12. Jafarzadeh $H$, Abbott PV. Dilaceration: review of an endodontic challenge. J Endod. 2007; 33(9): 1025-1030, doi: 10.1016/j. joen.2007.04.013, indexed in Pubmed: 17931926.

13. Kierklo A, Tabor Z, Petryniak R, et al. Application of microcomputed tomography for quantitative analysis of dental root canal obturations. Postepy Hig Med Dosw (Online). 
2014; 68: 310-315, doi: 10.5604/17322693.1095271, indexed in Pubmed: 24864081.

14. Milosevic A, Thomas J, Mitzman S. Satisfaction with dento-facial appearance in the eating disorders. Eur J Prosthodont Restor Dent. 2003; 11(3): 125-128, indexed in Pubmed: 14562650.

15. Oehlers FA. Dens invaginatus (dilated composite odontome). I. Variations of the invagination process and associated anterior crown forms. Oral Surg Oral Med Oral Pathol. 1957; 10(11): 1204-18 contd, doi: 10.1016/00304220(57)90077-4, indexed in Pubmed: 13477660.

16. Piszczatowski S, Baginska J, Swieszkowski W. Modeling of tooth's structure based on CT and $\mu \mathrm{CT}$ data - comparative study. IFMBE Proceedings. 2009: 1463-1466, doi: 10.1007/978-3-540-89208-3_347.

17. Primosch RE. Anterior supernumerary teeth--assessment and surgical intervention in children. Pediatr Dent. 1981; 3(2): 204-215, indexed in Pubmed: 6945564.
18. Rajasekharan S, Martens L, Vanhove C, et al. In vitro analysis of extracted dens invaginatus using various radiographic imaging techniques. Eur J Paediatr Dent. 2014; 15(3): 265-270, doi: 10.4172/scientificreports.147, indexed in Pubmed: 25306142.

19. Rodd HD, Marshman Z, Porritt J, et al. Oral healthrelated quality of life of children in relation to dental appearance and educational transition. Br Dent J. 2011; 211(2): E4, doi: 10.1038/sj.bdj.2011.574, indexed in Pubmed: 21779037.

20. Russell KA, Folwarczna MA. Mesiodens--diagnosis and management of a common supernumerary tooth. J Can Dent Assoc. 2003; 69(6): 362-366, indexed in Pubmed: 12787472.

21. Uysal S, Nazikoğlu A, Avuc N, et al. Dens in dente and fusion occurring in two supernumerary teeth: report of an unusual case. Hacettepe Dișhekimliği Fakültesi Dergisi. 2006; 30: 97-102. 